\author{
Radosław Cellmer*, Adam Senetra*, Agnieszka Szczepańska*
}

\title{
Land Value Maps of Naturally Valuable Areas**
}

\section{Evaluation of Environmental Factors}

Scenic value is an important determinant of real estate value, and it is the critical factor as regards the price of recreational and residential property. The significance of this factor is often marginalized in favor of location. Nonetheless, location and, to be more precise, its quality, is largely determined by the esthetic value of the surrounding space. Scenic features significantly contribute to the prices quoted on local property markets. The presence of greenery, forests, water and the arrangement of those spatial features directly affect buyer attitudes and the value of property.

There are various methods for representing scenic value and its influence on the remaining spatial phenomena. The most convenient method are isolines which connect points of equal numeric value.

Maps of esthetic values which present the existing condition of the landscape as the vector sum of all scenic components are rarely developed. Most analyses investigate constituent elements (water, forest, land elevation, etc.), and landscape maps which are land cover maps are created based on photographs (aerial, satellite), and they do not account for field observations. Scenic attractiveness is determined by one or more natural elements because the spontaneous presence of all desired features is sporadically noted. It should be stressed than not all landscape functions are represented at a given place and time.

\section{Methodology}

The correlation between scenic value and real estate function has an obvious effect on property prices. A varied landscape with elevation differences, a high share of forests and lakes is the preferred setting for residential and recreational areas.

* University of Warmia and Mazury in Olsztyn, Faculty of Geodesy and Land Management

** The article was supported by the Ministry of Science and Higher Education under the grant no. N N114 209540 
In this study, the effect of environmental factors on property value was determined using statistical and geostatistical methods. We set out to validate the theory that a sound knowledge of correlations between landscape features and transaction prices supports the development of land value maps based not only on information about prices but also scenic attributes.

Our methodological approach consisted of the following stages:

1. preparation of source data and space valuation,

2. analysis of spatial structure and spatial interpolation of selected environmental attributes,

3. analysis of spatial structure and spatial interpolation of transaction prices,

4. development of models describing the correlations between prices and environmental attributes,

5. compilation of value maps by cokriging.

For the needs of our analysis, we identified three sets of environmental attributes that influence property value:

- forest cover - was determined as the share of forests in the area of evaluation units;

- the presence of surface water bodies - this factor was determined as the share of surface water bodies and water courses in the area of evaluation units;

- land elevation - this attribute was determined as the number of contour lines intersecting the evaluation unit and its bisectors.

The above elements were identified during field studies and analyses of thematic maps. The assessment method was point valuation, and environmental quality was adapted as a variable in statistical analyses (Tab. 1).

Table 1. Valuation table for assessing landscape attractiveness

\begin{tabular}{|c|c|c|c|c|c|c|c|}
\hline \multicolumn{6}{|c|}{ Evaluated attributes } & \multicolumn{2}{|c|}{ Classification } \\
\hline \multicolumn{2}{|c|}{ land elevation } & \multicolumn{2}{|c|}{ forest cover } & \multicolumn{2}{|c|}{ surface water } & \multirow{2}{*}{$\begin{array}{l}\text { sum of } \\
\text { values } \\
\text { [points] }\end{array}$} & \multirow{2}{*}{$\begin{array}{c}\text { landscape } \\
\text { attractiveness } \\
\text { category }\end{array}$} \\
\hline $\begin{array}{l}\text { number of } \\
\text { intersections }\end{array}$ & $\begin{array}{c}\text { value } \\
\text { [points] }\end{array}$ & $\begin{array}{c}\text { forest area } \\
{[\%]}\end{array}$ & $\begin{array}{c}\text { value } \\
\text { [points] }\end{array}$ & $\begin{array}{c}\text { area of } \\
\text { water } \\
\text { bodies [\%] }\end{array}$ & $\begin{array}{c}\text { value } \\
\text { [points] }\end{array}$ & & \\
\hline$\leq 25$ & 1 & none & 0 & none & 0 & $\leq 7$ & $\begin{array}{c}(\mathrm{IV}) \\
\text { unattractive }\end{array}$ \\
\hline $26-50$ & 2 & $<25$ & 2 & $<20$ & 4 & 8-11 & $\begin{array}{l}\text { (III) relatively } \\
\text { unattractive }\end{array}$ \\
\hline $51-75$ & 3 & $25-50$ & 4 & $20-80$ & 8 & $12-16$ & (II) attractive \\
\hline$>75$ & 4 & $>50$ & 6 & $>80$ & 12 & $\geq 17$ & $\begin{array}{l}\text { (I) highly } \\
\text { attractive }\end{array}$ \\
\hline
\end{tabular}

Source: own study based on [5] 
The studied area was divided into a grid of 425 evaluation units which were squares with a side length of $500 \mathrm{~m}$. The area of an evaluation unit was a compromise between the range of information that can be acquired from a single area and the possibility of generalizing the obtained data.

Basic evaluation units were classified in view of their scenic appeal. None of the units were graded in the highest attractiveness category I. The above can be attributed to the presence of large water bodies which significantly limit elevation differences, a key determinant of landscape attractiveness. Territories classified as attractive (category II) occupied less than 15\% of the surveyed sites.

An analysis of the indicators of spatial variability involves the determination of the empirical value of differences between variables, measured at two different points, as a function of distance between those points, and modeling the resulting correlations. In the modeling process, spatial variability is described by a mathematical function where the argument is the vector of distance between data points [7].

The spatial structure of environmental factors and transactional prices may be analyzed based on the correlations presented in the form of semivariograms. An empirical semivariogram can be calculated using the following formula $[4,9,13,14,16]$ :

where:

$$
\tilde{a}(h)=\frac{1}{2 N(h)} \sum_{i=1}^{N(h)}\left[Z\left(x_{i}+h\right)-Z\left(x_{i}\right)\right]^{2}
$$

$$
\begin{aligned}
& Z\left(x_{i}\right) \text { - value of data, } \\
& x_{i} \text { - location of sites where measurements were performed, } \\
& N(h) \text { - number of pairs of points }\left(x_{i^{\prime}} x_{i}+h\right) \text { separated by distance } h .
\end{aligned}
$$

The semivariogram function indicates the rate at which the mutual relations between variables decrease with an increase in distance. The spatial correlation between environmental attributes and property prices in different locations is determined mainly by similarities in location features, such as availability, neighborhood and surroundings. Therefore, we can make an a priori assumption that a real estate market is characterized by a spatial autocorrelation of transaction prices because the similarity of location also implies the convergence of key price-forming factors. According to Bourassa, Cantoni and Hoesli [2], the spatial structure of prices can be investigated with the use of the appropriate variogram models.

In principle, environmental attributes can be evaluated only in selected points of measurement (e.g. in the centroid of an evaluation unit). Therefore, if we assume that the adopted values of environmental attributes have a continuous character, spatial interpolation can be performed with the use of deterministic or geostatistical methods. In our study, we used ordinary kriging methods which rely on previously defined regularities in the form of a semivariogram. Kriging is a group of geostatistical estimation methods which produce linear unbiased value estimators of the analyzed regionalized variable. The value estimated by kriging is a weighted linear combination of regionalized random values. 
The kriging estimator represented by random function $Z\left(s_{i}\right)$ takes on the following value:

$$
Z^{*}\left(s_{0}\right)=\sum_{i=1}^{n} w_{i} Z\left(s_{i}\right)
$$

where $w_{i}$ are kriging weights. Those weights are calculated on the assumption of minimized error variance. In ordinary kriging, the sum of weights is constrained to be one.

Kriging and its technical and scientific applications are widely discussed in literature, and the possibilities offered by kriging methods are the subject of an ongoing debate $[1,3,8,10,16]$. The use of kriging in spatial analysis of property transaction prices has also been described in detail by various authors $[2,12,15]$.

If the main variable, in this case - the transaction price, is significantly correlated with additional variables, i.e. environmental attributes, cokriging methods can be applied to integrate data and develop a land value map. The use of cokriging is justified when the main variable can be measured (or read) only at selected points, but additional variables are easy to measure at any point. In this study, cokriging can be used to forecast values at points where very few or no transactions have been registered. The ordinary kriging estimator is a linear combination of weights and data representing variables at sample points in the vicinity of estimated point $s_{0}$ :

$$
Z^{*}\left(s_{0}\right)=\sum_{j=1}^{N} \sum_{i=1}^{n} w_{i}^{j} Z_{j}\left(s_{i}\right)
$$

where $N$ is the number of additional variables. Weights are selected in such a way as to minimize error variance. Detailed information about the theory of kriging and its practical applications can be found in literature [6, 11, 17]

\section{Object of the Study and Source Data}

The study investigating the impact of environmental attributes on the prices and value of real estate was performed in a selected area in north-eastern Poland which is characterized by high natural and scenic value. The investigated territory was a rural municipality situated around $10 \mathrm{~km}$ from Olsztyn, the region's capital city with a population of 180,000. The examined site's attractiveness can be attributed to the proximity of a large agglomeration (capital city of the region) and, above all, its high scenic appeal resulting from the presence of lakes usable for recreational purposes, large forest complexes, and post-glacial landscape which is characteristic of this part of Poland.

The main sources of information about environmental factors in the analyzed area were topographic maps and field observations. Real estate data comprised transactions 
in undeveloped land plots zoned for residential or recreational development. After preliminary selection, 127 transactions conducted in the previous five years were adopted for the needs of this study. The unit prices of the analyzed real estates ranged from

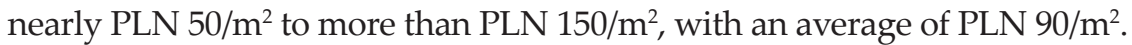

\section{Results}

In our study, special emphasis was placed on three key environmental attributes: the presence of surface water bodies such as lakes, ponds and watercourses, forest cover and land elevation. The investigated areas were analyzed based on evaluation units which were squares with a side length of $500 \mathrm{~m}$. The presence of lakes, forests and land surface features was assessed independently in each evaluation unit. A section of the map of the analyzed area with a division into evaluation units and the location of property transactions is presented in figure 1.

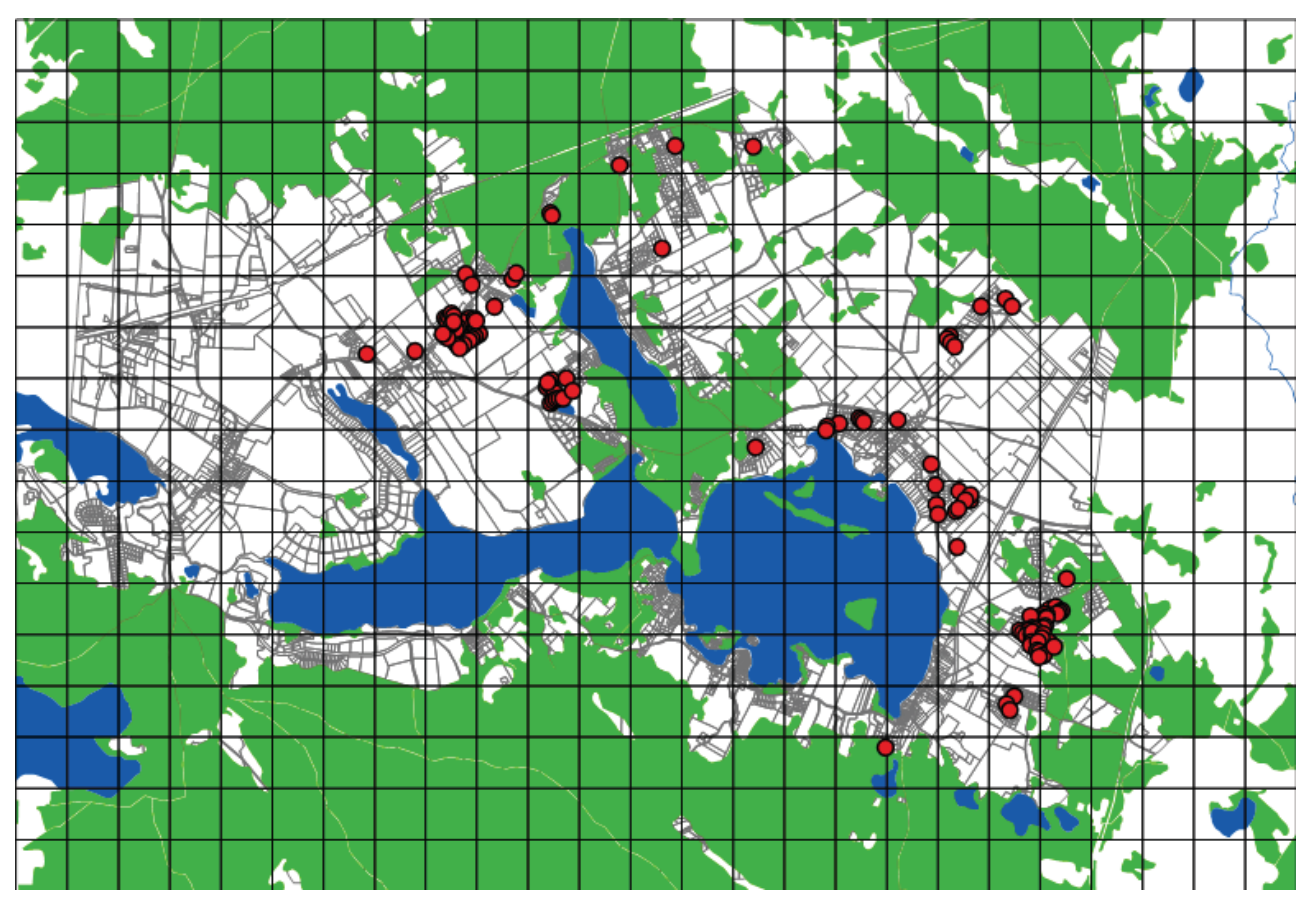

Fig. 1. Map of the analyzed area with a division into evaluation units and the location of property transactions

The spatial structure of the analyzed environmental attributes was expressed in the form of variograms and maps developed by ordinary kriging. The investigated factors were characterized by spatial autocorrelation (Fig. 2). 
Water

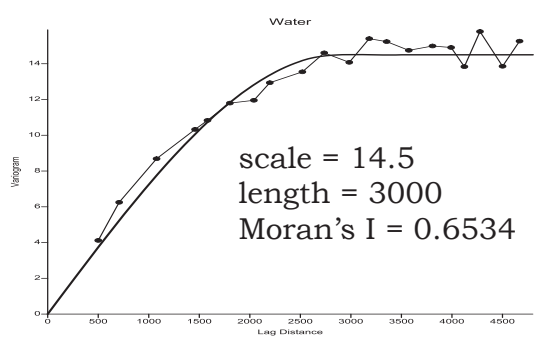

Elevation

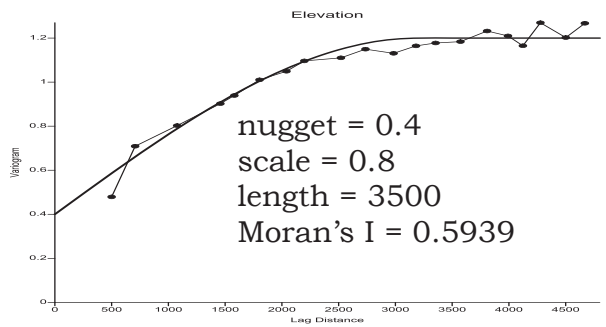

Forests

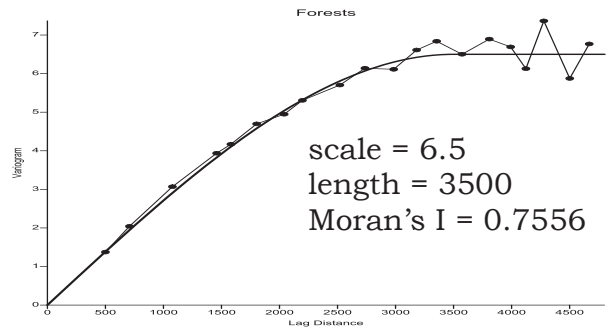

Sum Point

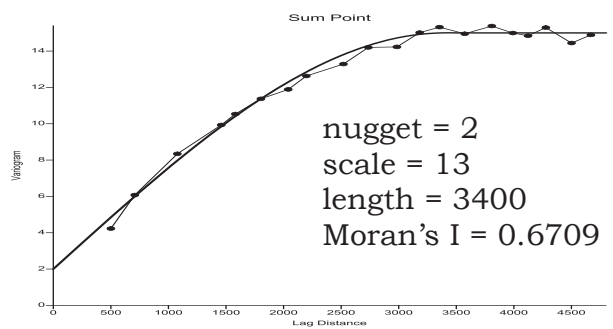

Fig. 2. Spatial structure of the analyzed environmental attributes expressed in the form of semivariograms

The range of semivariograms insignificantly exceeded $3 \mathrm{~km}$, and the above distance mapped the spatial similarity of the analyzed attributes. Spatial autocorrelation measured by Moran's I revealed significant spatial correlations and continuous variability of environmental attributes.

A spatial structure analysis indicates that kriging interpolation is the most effective method for the cartographic representation of variability in the analyzed environmental attributes in space. A map of environmental attributes as the sum of numerical values assigned to every attribute is presented in figure 3 .

As a result of a spatial analysis of environmental attributes, the location of every transacted property was assigned numerical values indicative of the proximity of water bodies, forest cover and land elevation. Additional characteristics of every analyzed transactions were thus obtained, and they were used to investigate correlations between land prices and environmental attributes. The spatial structure of transaction prices was also presented in the form of a semivariogram (Fig. 4). A spherical model with a nugget effect was also applied in this case. Fitting the distribution to a theoretical model produced less congruent results. The semivariogram had the range of around $1700 \mathrm{~m}$. It could be hypothesized that this was the limit of locational similarity which was represented by the variability of unit prices.

The empirical distribution of unit prices is characterized by rightward skewness which is characteristic of the real estate market (predominance of below average prices). 


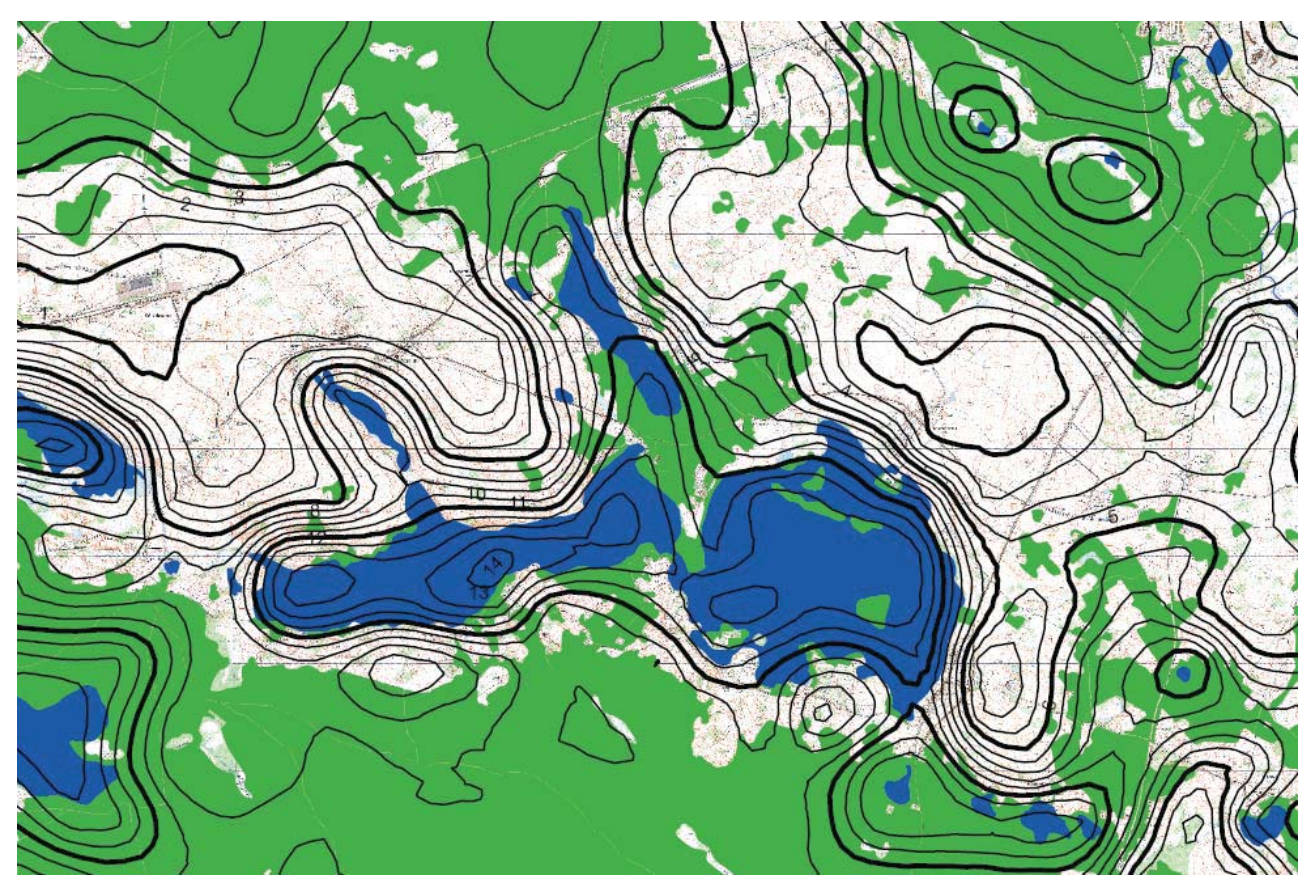

Fig. 3. Map of environmental attributes

(as a sum of numerical values assigned to every attribute)

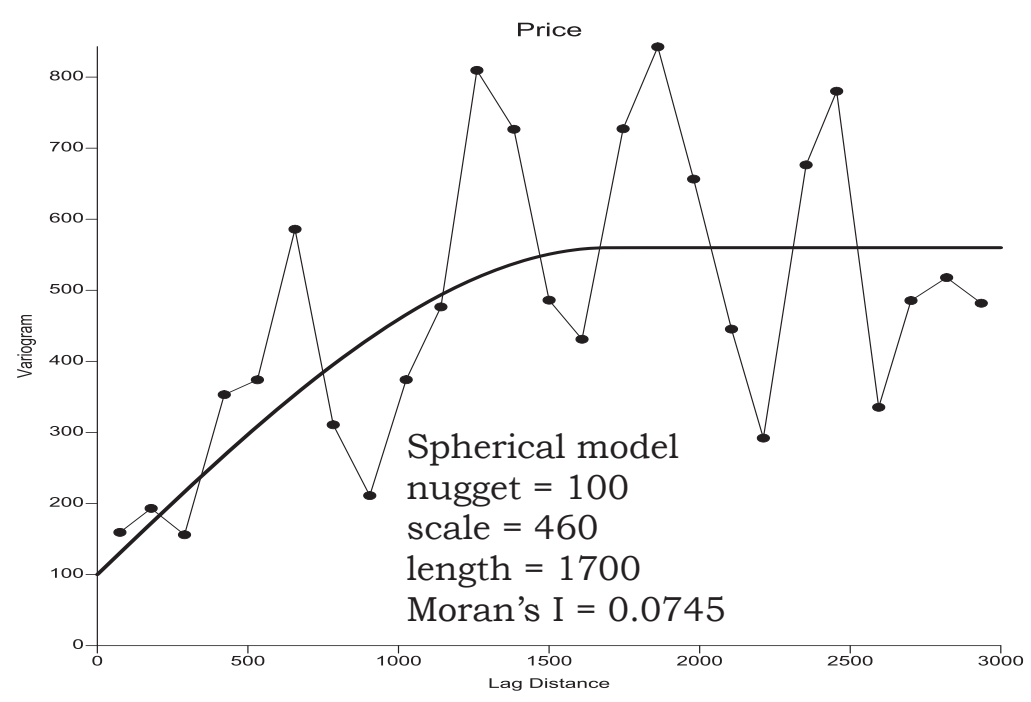

Fig. 4. Spatial structure of transaction prices 
The results presented in the form of a multiple regression model suggests that the presence of water bodies and forests has a significant impact on transaction prices (Tab. 2). Elevation is also a crucial determinant of environmental attractiveness, but its low impact on land prices can be explained by the fact that high differences in elevation are not a desirable feature in housing construction. The studied area was characterized by an abundance of water bodies, therefore, its elevation was not highly diversified.

Table 2. Multiple regression analysis results

\begin{tabular}{||l|c|c|c|c||}
\hline \multicolumn{5}{|c||}{$\begin{array}{c}\text { Regression summary for dependent variable: price } \\
R^{2}=0.33 F=6.29\end{array}<0.0005$} \\
\hline \multicolumn{1}{||c|}{ variable } & $\beta$ & std. error $\beta$ & $t$ & $p$-level \\
\hline \hline Intercept & 72.409 & 11.796 & 6.138 & 0.000 \\
\hline Water & 5.015 & 1.547 & 3.240 & 0.001 \\
\hline Forests & 4.376 & 1.527 & 2.865 & 0.004 \\
\hline Elevation & 3.724 & 5.733 & 0.649 & 0.517 \\
\hline
\end{tabular}

The information about correlations between transaction prices and environmental attributes can be used to develop land value maps, in particular in areas where transaction price data are in short supply or are unavailable. Ordinary cokriging methods were used where the main variable was the transaction price, whereas additional variables included the proximity and access to water bodies and forest cover. The results in the form of a land value map are presented in figure 5 .

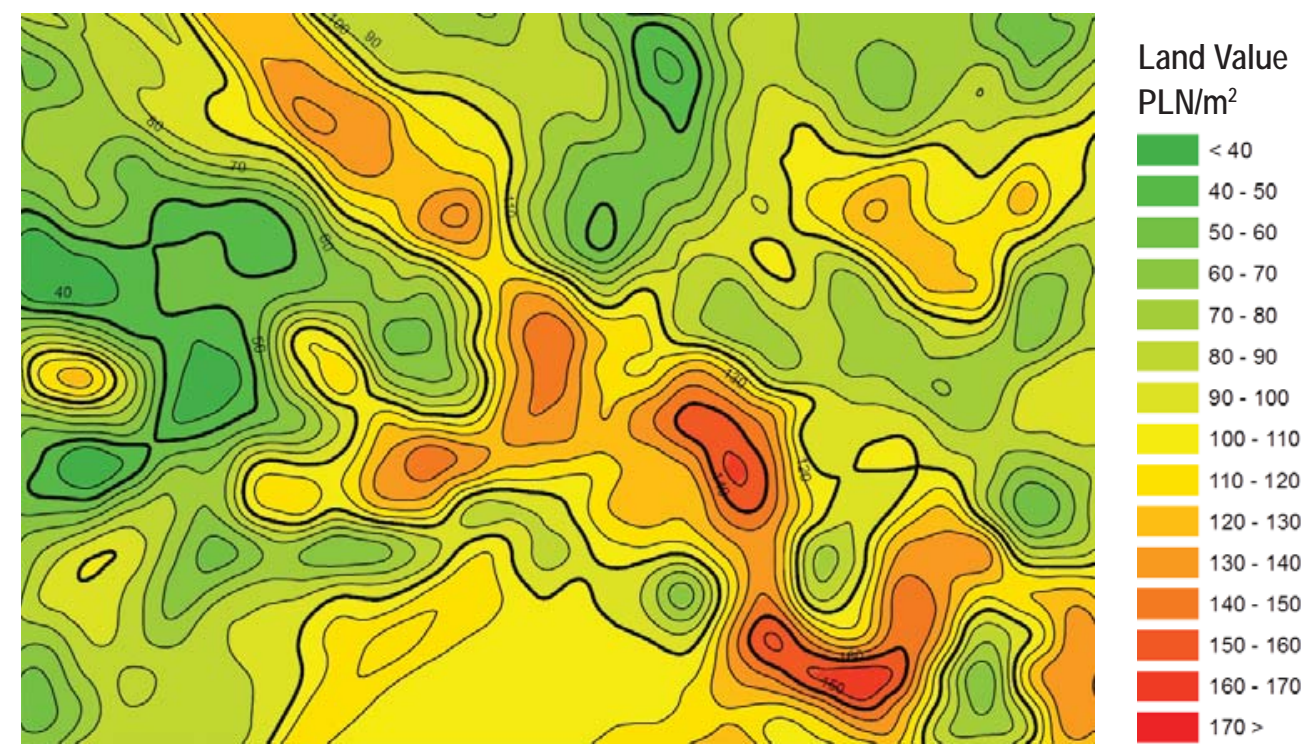

Fig. 5. Land value map in the analyzed area developed by cokriging 
The land value map was developed based on transaction prices as well as the spatial structure of main environmental attributes that affect those prices. The above implies that in areas of high environmental value, the forecast prices are higher than in regions with a lower scenic attractiveness rating.

\section{Conclusions}

The proposed method for analyzing the impact of environmental attributes on the value and prices of property may be a helpful tool in real estate management and spatial planning. It is particularly useful in areas of high scenic value which have been zoned for recreational and residential development. Cokriging supports the development of land value maps when prices are correlated with variables that are easy to measure based on the existing sources of data. The discussed methods can be deployed not only in environmentally valuable areas, but also in regions where market data are available and the spatial structure of environmental attributes that shape transaction prices is known.

\section{References}

[1] Bárdossy A.: Introduction to Geostatistics. Institute of Hydraulic Engineering, University of Stuttgart, 1997.

[2] Bourassa S.C., Cantoni E., Hoesli M.: Spatial Dependence, Housing Submarkets, and House Price Prediction. Journal of Real Estate Finance and Economics, vol. 35, 2007, pp. 143-160.

[3] Burrough P.A.: GIS and geostatistics. Essential partners for spatial analysis. Environmental and Ecological Statistics, vol. 8, 2001, pp. 361-377.

[4] Cressie N.: Statistics for spatial data. Wiley Interscience, 1993.

[5] Dąbrowski H.: Planowanie przestrzenne. Wydawnictwo Akademii Rolniczo-Technicznej, Olsztyn 1990.

[6] Eldeiry A., Garcia L. A.: Comparison of Regression Kriging and Cokriging Techniques to Estimate Soil Salinity Using Landsat Images. AGU Hydrology Days, March 25-27, 2009.

[7] Isaaks E.H., Srivastava R.M.: An Introduction to Applied Geostatistics. Oxford University Press, New York 1989.

[8] Goovaerts P.: Ordinary Kriging Revisited. Mathematical Geology, 30 (1), 1998, pp. 21-42.

[9] Journel A.G., Huijbregts C.J., Mining Geostatistics. Academic Press, London 1978.

[10] Maantay J.A., McLafferty S.N., Geospatial Analysis of Environmental Health. Springer Science Business Media B.V., 2001. 
[11] Malvić T., Barišić M., Futivić I.: Cokriging geostatistical mapping and importance of quality of seismic attribute(s). Nafta, vol. 60 (5), 2009, pp. 259-264.

[12] Martinez M.: Kriging Methodology for Regional Economic Analysis: Estimating the Housing Price in Albacete. International Advances in Economic Research, vol. 6 (3), 2000, pp. 438-450.

[13] Matheron G.: Kriging or Polynomial Interpolation Procedures? CIMM Transactions, vol. 70, 1967, pp. 240-244.

[14] Matheron G.: The theory of regionalized variables and its applications. Ecole Nationale Superieure des Mines de Paris, 1971.

[15] Páez A.: Recent research in spatial real estate hedonic analysis. Journal of Geographical Systems, vol. 11 (4), 2009, pp. 311-316.

[16] Sarma D.D.: Geostatistics with Applications in Earth Sciences. Springer, 2009.

[17] Yalçin E.: Cokriging and its effect on the estimation precision. The Journal of The South African Institute of Mining and Metallurgy, vol. 105, 2005, pp. 223-228. 